\title{
Dendrimers: Prospects for Bioanalytical Sciences
}

\section{Sandeep Kumar Vashist}

HSG-IMIT, Institut für Mikro- und Informationstechnik, Georges-Koehler-Allee 103, 79110 Freiburg, Germany

Dendrimers are repetitively branched molecules that have a typically symmetric core, an inner shell and an outer shell (Figure 1). The term 'dendrimers' was derived from the Greek word 'dendra' that means tree. They are generally classified by the generation, which is determined by the number of repeated branching cycles performed during its synthesis (Figure 1). The molecular weight of the dendrimer increases after each successive generation i.e. about twice than that of the previous generation. The higher generations dendrimers have increased surface functional groups, which determine their characteristic properties and make them suitable for various bioanalytical applications [1-4]. They enable the effective control of their solubility, thermal stability, crystallinity, chirality, tecto-dendrimer formation, toxicity and bioconjugation. The most commonly used dendrimers (Figure 2) are based on polyamidoamines, polyamides (polypeptides), polyamines, polyesters, poly(aryl ethers), DNA and carbohydrates.

Initially, dendrimers were prepared by divergent synthesis [5], but the introduction of convergent synthetic approach for the preparation of dendrimers by Jean Fréchet [6] in 1990 led to exponential increase in dendrimers-based bioanalytical applications, as evident from $>10,000$ scientific papers published from 2000 onwards. The divergent synthesis involved extending the core of dendrimer outwards by a series of reactions, which usually leads to impurities and defects in dendrimer. But the convergent synthesis involves the reactions from the outermost spherical surface towards the innermost core of the dendrimer, where the impurities and shorter branches can be easily removed, thereby leading to monodisperse dendrimers. The synthesis of dendrimers by both approaches involves many steps, which is a serious limitation to synthesize them in bulk. Therefore, they are very expensive and being

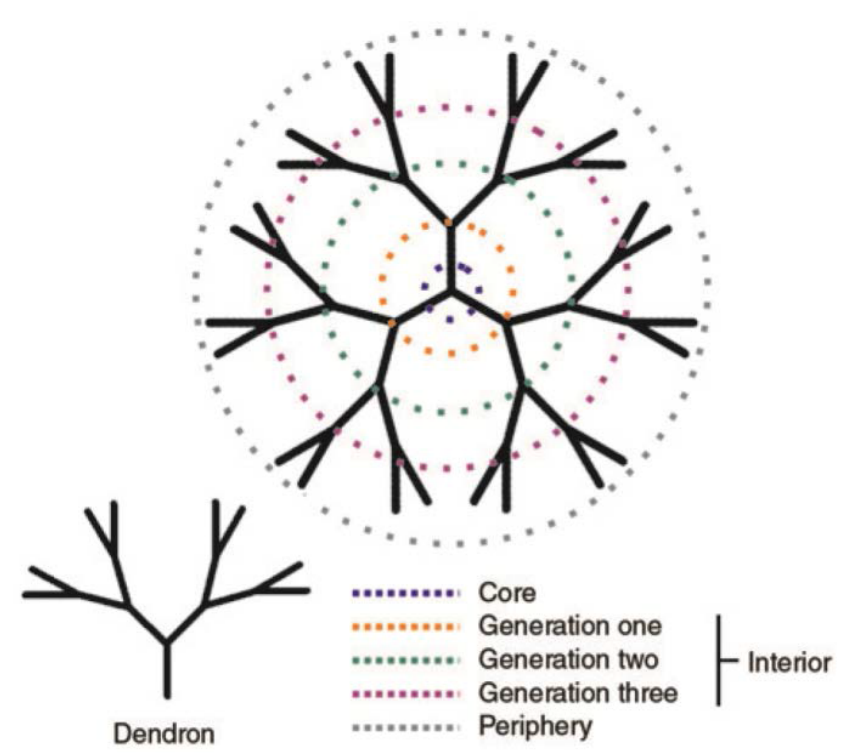

Figure 1: Structure of a dendrimer [3]. Reproduced with permission from Nature Publishing Group. synthesized by selected companies only. The click chemistry has also been employed for synthesizing dendrimers [7-10]. Poly(amidoamine) (PAMAM) is the most widely used dendrimer for bioanalytical applications that is commercially-available in various generations, while its numerous surface functional groups make it ideal for click chemistry. It has a diamine (usually ethylene diamine) core, which reacts sequentially with methyl acrylate and ethylenediamine to make generation-0 (G-0) PAMAM. The lower generations i.e. G-0 to G-2 are flexible molecules with no appreciable inner regions; G-3 and G-4 have well-defined internal space; and, G7 and higher PAMAM dendrimers are solid particles with highly dense surfaces.

Dendrimers are multivalent systems, which can be conjugated to various chemical species, such as detection agents, imaging agents, targeting components, biomolecules, pharmaceutical/therapeutic agents, radio ligands, affinity ligands, for various bioanalytical applications. The water-soluble carboxylic acid and phenol terminated dendrimers have been widely used in drug delivery and for conducting chemical reactions in their interior. Dendrimers allow the simultaneous conjugation of targeting and drug molecules, which significantly reduces the negative side-effects of drug molecules on the healthy cells. They are widely employed for hosts guest chemistry and as a solubilizing agent. Due to their micelle-like behaviour based on their hydrophobic core and hydrophilic periphery, they can be used to encapsulate and solubilize majority of pharmaceutical drugs that are hydrophobic in nature. They have been widely used for the controlled delivery of antiretroviral bioactives [11] and anti-cancer drugs, such as cisplatin [12] and methotrexate [13]. The use of dendrimers enhances the uptake and retention of compounds within cancer cells.

Dendrimers have been extensively used for sensor applications, such as detection of $\mathrm{pH}$ using poly(propylene imine) [14]; detection of fluorescence signal quenching using cadmium-sulfide/ polypropylenimine tetrahexacontaamine [15]; and, photodetection of metal cation using G-1 and G-2 poly(propylenamine) [16]. They can also be used as blood substitutes as their steric bulk surrounding the heme-mimetic centre slows the degradation in comparison to free heme $[17,18]$ apart from preventing the cytotoxicity exhibited by free heme. Additionally, PAMAM dendrimers have been used for synthesizing metallic nanoparticles of $1.5-10 \mathrm{~nm}$ diameter, known as dendrimerencapsulated nanoparticles [19]. Dendrimers have also been used for photonic oxygen sensing $[20,21]$ and as carriers for magnetic

*Corresponding author: Sandeep Kumar Vashist, HSG-IMIT, Institut für Mikro- und Informationstechnik, Georges-Koehler-Allee 103, 79110 Freiburg, Germany, Tel: +49 761 2037252; Fax: +49 76120373299 ; E-mail: sandeep.kumar.vashist@hsg-imit.de

Received September 30, 2013; Accepted October 01, 2013; Published October 03, 2013

Citation: Vashist SK (2013) Dendrimers: Prospects for Bioanalytical Sciences. J Nanomed Nanotechnol 4: e131. doi:10.4172/2157-7439.1000e131

Copyright: @ 2013 Vashist SK. This is an open-access article distributed under the terms of the Creative Commons Attribution License, which permits unrestricted use, distribution, and reproduction in any medium, provided the original author and source are credited. 
a

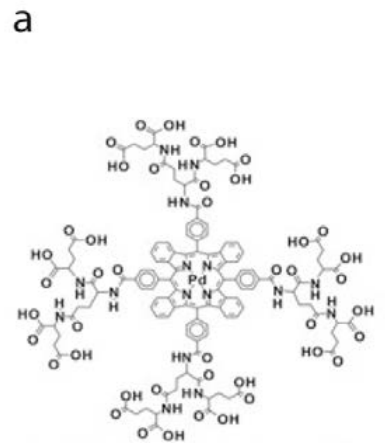

Poly(glutamic acid) dendrimer (G-2)

\section{b}

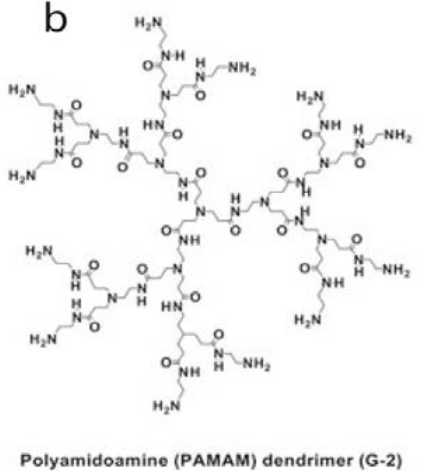

C

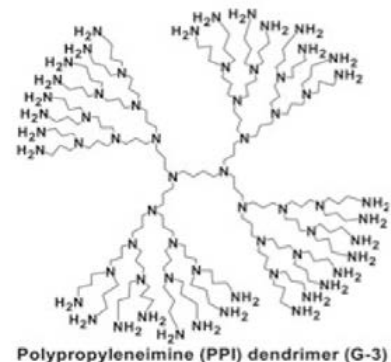

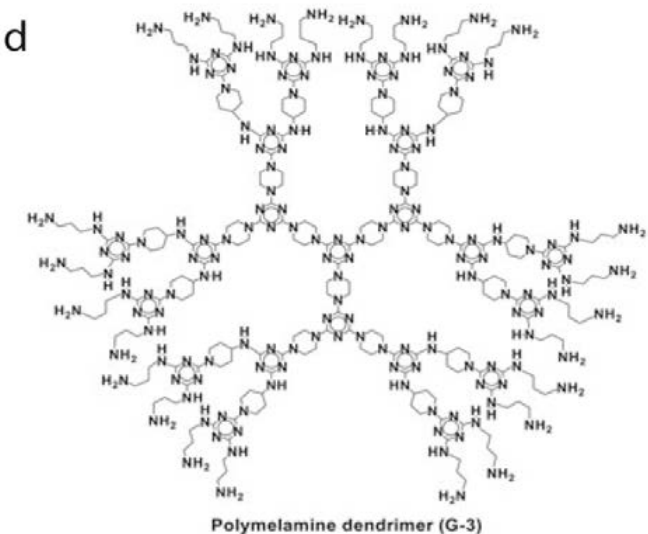

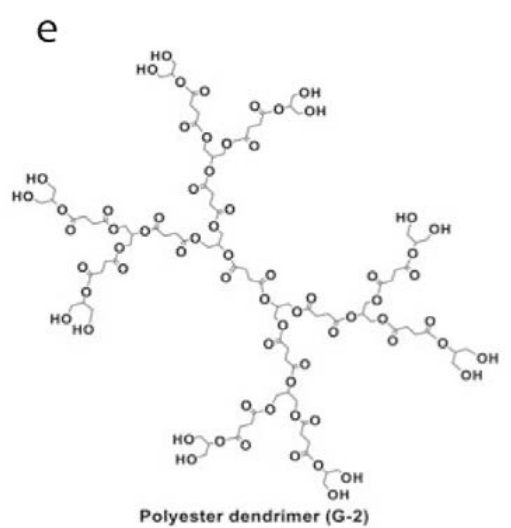

Figure 2: Dendrimers being used in bioanalytical sciences [3]. (a) G-2 poly(glutamic acid) dendrimer. (b) G-2 polyamidoamine (PAMAM) dendrimer. (c) G-3 polypropyleneimine (PPI) dendrimer. (d) G-3 polymelamine dendrimer. (e) G-2 polyester dendrimer. Reproduced with permission from Nature Publishing Group.

resonance imaging contrast reagents [22,23]. Some dendrimers have also been used as drugs, such as PAMAM dendrimers that stimulate the removal of prion proteins from the infected cells [24]. They inhibit the multivalent binding between cells, bacteria, viruses and proteins [25]. A G-4 poly(L-lysine) dendrimer, having sulfate groups at its periphery, has been evaluated as an anti-viral topical ointment [26,27].

The significant advances during the last two decades have led to biodegradable chemistries, which enable the use of dendrimers for drug delivery, therapeutics, tissue repair scaffolds and optical oxygen sensors. The effects of molecular weight and design of dendrimers on their in vivo behaviour have also been well-understood. The low molecular weight dendrimers are expected to be highly biocompatible and should have fast renal elimination or biodegradation rate. However, there is still an immense need to assess the long-term human and environmental health consequences of exposure to dendrimers in vivo. Moreover, improved quality control assays are required to ensure the composition of dendrimers. The analytical procedures for synthesizing dendrimers are too complex and tedious, which need to be significantly improved in order to significantly cut down the commercial cost of dendrimers and enable them to be synthesized in bulk quantities. Lastly, the dendrimer-based bioanalytical applications need to comply with the existing industrial and healthcare requirements $[28,29]$.

\section{References}

1. Bosman AW, Janssen HM, Meijer EW (1999) About dendrimers: structure physical properties, and applications. Chem Rev 99: 1665-1688.

2. Gajbhiye V, Palanirajan VK, Tekade RK, Jain NK (2009) Dendrimers as therapeutic agents: a systematic review. J Pharm Pharmacol61: 989-1003.

3. Lee CC, MacKay JA, Fréchet JM, Szoka FC (2005) Designing dendrimers for biological applications. Nat Biotech 23: 1517-1526.

4. Astruc D, Boisselier E, Ornelas C (2010) Dendrimers designed for functions: from physical, photophysical, and supramolecular properties to applications in sensing, catalysis, molecular electronics, and nanomedicine.. Chem Rev 110: 1857-1959.

5. Tomalia DA, Baker H, Dewald J, Hall M, Kallos G, et al. (1985) A New Class of Polymers: Starburst-Dendritic Macromolecules. Polym J 17: 117-132.

6. Hawker CJ, Fréchet JMJ (1990) Preparation of polymers with controlled molecular architecture. Anew convergent approach to dendritic macromolecules. J Am Chem Soc 112: 7638-7647.

7. Noda K, Minatogawa Y, Higuchi T (1991) Effects of hippocampal neurotoxicant trimethyltin, on corticosterone response to a swim stress and glucocorticoid binding capacity in the hippocampus in rats. Jpn J Psychiatry Neurol 45: 107108.

8. Franc G, Kakkar A (2008) Dendrimer Design Using Cu(I)-Catalyzed AlkyneAzide Click Chemistry. Chem Comm 14: 5267-5276.

9. Killops KL, Campos LM, Hawker CJ (2008) Robust, Efficient, and Orthogonal Synthesis of Dendrimers via Thiol-ene "Click" Chemistry. J Am Chem Soc 130: 5062-5064. 
10. Franc G, Kakkar AK (2009) Diels-Alder "Click" Chemistry in Designing Dendritic Macromolecules. Chem Eur J 15: 5630-5639.

11. Dutta T, Jain NK (2007) Targeting Potential and Anti HIV activity of mannosylated fifth generation poly(propyleneimine) Dendrimers. Biochimica et Biophysica Acta 1770: 681-686

12. Malik N, Evagorou EG, Duncan R (1999) Dendrimer-platinate: a novel approach to cancer chemotherapy. Anticancer Drugs 10: 767-776.

13. Kukowska-Latallo JF, Candido KA, Cao Z, Nigavekar SS, Majoros IJ, et al. (2005) Nanoparticle targeting of anticancer drug improves therapeutic response in animal model of human epithelial cancer. Cancer Res 65: 5317-5324.

14. Fernandes EGR, Vieira NCS, de Queiroz AAA, Guimaraes FEG, Zucolotto $\checkmark$ (2010) Immobilization of Poly(propylene imine) Dendrimer/Nickel Phthalocyanine as Nanostructured Multilayer Films To Be Used as Gate Membranes for SEGFET pH Sensors. J PHYS CHEM C 114: 6478-6483.

15. Campos BB, Algarra M, da Silva E, Joaquim CG (2010) Fluorescent Properties of a Hybrid Cadmium Sulfide-Dendrimer Nanocomposite and its Quenching with Nitromethane. J Fluoresc 20: 143-151.

16. Grabchev I, Staneva D, Chovelon JM (2010) Photophysical investigations on the sensor potential of novel, poly(propylenamine) dendrimers modified with 1,8-naphthalimide units. Dyes and Pigments 85: 189-193.

17. Twyman LJ, Ge Y (2006) Porphyrin cored hyperbranched polymers as heme protein models. Chem Comm 15: 1658-1660.

18. Twyman LJ, Ellis A, Gittins PJ (2012) Pyridine encapsulated hyperbranched polymers as mimetic models of haeme containing proteins, that also provide interesting and unusual porphyrin-ligand geometries. Chem Comm 48: 154156.

19. Scott RW, Wilson OM, Crooks RM (2005) Synthesis, Characterization, and Applications of Dendrimer-Encapsulated Nanoparticles. J Phys Chem B 109: 692-704.

20. Dunphy I, Vinogradov SA, Wilson DF (2002) Oxyphor R2 and G2: phosphors for measuring oxygen by oxygen-dependent quenching of phosphorescence. Anal Biochem 310: 191-198.
21. Briñas RP, Troxler T, Hochstrasser RM, Vinogradov SA (2005) Phosphorescent oxygen sensor with dendritic protection and two-photon absorbing antenna. $J$ Am Chem Soc 127: 11851-11862.

22. Wiener E, Brechbiel MW, Borthers H, Magin RL, Gansow OA, et al. (1994) Dendrimer-based metal chelates: a new class of magnetic resonance imaging contrast agents. Magn Reson Med 31: 1-8.

23. Margerum LD, Campion BK, Koo M, Shargill N, Lai JJ, et al. (1997) Gadolinium(III) DO3A macrocycles and polyethylene glycol coupled to dendrimers. Effect of molecular weight on physical and biological properties of macromolecular magnetic resonance imaging contrast agents. J Alloys Compd 249: $185-190$.

24. Supattapone S, Nguyen HOB, Cohen FE, Prusiner SB, Scott MR (1999) Elimination of prions by branched polyamines and implications for therapeutics. Proc Natl Acad Sci 96: 14529-14534.

25. Roy R, Baek MG (2002) Glycodendrimers: novel glycotope isosteres unmasking sugar coding. Case study with T-antigen markers from breast cancer MUC1 glycoprotein. J Biotechnol 90: 291-309.

26. Jiang YH, Emau P, Cairns JS, Flanary L, Morton WR, et al. (2005) SPL7013 gel as a topical microbicide for prevention of vaginal transmission of SHIV89.6P in macaques. AIDS Res Hum Retroviruses 21: 207-213.

27. Bourne N, Stanberry LR, Kern ER, Holan G, Matthews B, et al. (2000) Dendrimers, a new class of candidate topical microbicides with activity against herpes simplex virus infection. Antimicrob Agents Chemother 44 (2000) 24712474.

28. Vashist SK, Venkatesh AG, Mitsakasis K, Czilwik G, Roth G, et al. (2012) Nanotechnology-based biosensors and diagnostics: technology push versus industrial/healthcare reuirements. BioNanosci 2: 115-126.

29. Vashist SK (2013) Nanomaterials-based health care and bioanalytical applications: trend and prospects. J Nanomater Mol Nanotechnol 2. 